\title{
Phorbol Esters Mimic Some Cholinergic Actions in Hippocampal Pyramidal Neurons
}

\author{
Robert C. Malenka, Daniel V. Madison, Rodrigo Andrade, and Roger A. Nicoll \\ Departments of Pharmacology and Physiology, University of California, San Francisco, California 94143
}

\begin{abstract}
Muscarinic receptor stimulation in the hippocampus has been associated with inositol phospholipid breakdown. In other systems this leads to the formation of inositol trisphosphate and diacylglycerol, which promotes the activation of protein kinase C. Phorbol esters, which directly activate protein kinase $\mathrm{C}$, exhibit high and specific binding in the hippocampus. This, along with the advantages of the hippocampal slice preparation, including direct pharmacological access to a cell population (CA1 pyramidal cells) having clearly defined muscarinic responses, makes this an ideal preparation to examine whether protein kinase $\mathrm{C}$ serves as the intracellular signal for muscarinic receptor occupation. Like muscarinic agonists, phorbol esters abolish the slow calcium-activated potassium afterhyperpolarizing potential (AHP) and its underlying current without reducing calcium action potentials. Those phorbol analogs that do not activate kinase $C$ have no effect, suggesting that activation of this enzyme is required to reduce the AHP. The accommodation of spike discharge normally seen during a long depolarizing stimulus is also markedly reduced by phorbol esters as well as by muscarinic receptor activation. However, unlike muscarinic agonists, phorbol esters have no effect on the muscarine-sensitive, voltage-dependent, potassium current termed $I_{\mathrm{M}}$, nor do they consistently cause an increase in input resistance. Moreover, unlike $\mathrm{ACh}$, they do not appear to have a presynaptic inhibitory action on the fast EPSP elicited by orthodromic stimulation. The slow cholinergic EPSP was blocked by phorbol esters, but this could be accounted for by a postsynaptic action. Thus, if inositol phospholipid turnover is involved in mediating muscarinic responses in the hippocampus, the activation of protein kinase $\mathbf{C}$ can account for only part of the electrophysiological response.
\end{abstract}

A common electrophysiological property of CNS neurons is that the frequency of spike discharge declines during a constant depolarizing stimulus. This accommodation or adaptation in hippocampal pyramidal cells is due in large part to a calciumactivated potassium conductance (Madison and Nicoll, 1984). It appears that a number of putative neurotransmitters, including acetylcholine (ACh) (Benardo and Prince, 1982; Cole and Nicoll, 1984a), norepinephrine (Haas and Konnerth, 1983; Madison and Nicoll, 1982), histamine (Haas and Konnerth, 1983), and corticotropin releasing factor (Aldenhoff et al., 1983), can modulate the output of pyramidal cells by reducing accommodation through a blockade of calcium-activated potassium conductance. Norepinephrine acting on $\beta$ receptors is thought

Received May 6, 1985; revised July 1, 1985; accepted July 3, 1985.

This work was supported by Grants MH-38256, MH-00437 (RSDA to R.A.N.), NS-07495 (to R.C.M.), MH-09180 (to R.A.), the Scottish Rite Schizophrenia Research Program, NMJ, U.S.A., and the Klingenstein Fund.

Correspondence should be addressed to Dr. Nicoll, at Department of Pharmacology, S1210, University of California, San Francisco, San Francisco, CA 94143.

Copyright (C) 1986 Society for Neuroscience $0270-6474 / 86 / 020475-06 \$ 02.00 / 0$ to exert this effect via the second messenger cAMP (Madison and Nicoll, 1982). While this mechanism might also account for the actions of some of the other putative neurotransmitters, it is unlikely to explain muscarinic effects on pyramidal cells. There is little evidence in any system that the actions of ACh are mediated by stimulation of adenylate cyclase and the possible involvement of cGMP in cholinergic responses is as yet unsettled (Cole and Nicoll, 1984b; Volle, 1983).

In a number of model systems, muscarinic receptors appear to signal their actions by eliciting the breakdown of inositol phospholipids, leading to the production of inositol trisphosphate and diacylglycerol, a promoter of protein kinase $\mathrm{C}$ activity (Nishizuka, 1984). In the hippocampus, carbachol, acting on muscarinic receptors, has been shown to elicit the breakdown of inositol phospholipids (Downes, 1982; Janowsky et al., 1984; Labarca et al., 1984), suggesting that this transduction mechanism might also mediate muscarinic responses in this region. Consistent with this possibility, high concentrations of binding sites for phorbol esters, a class of compounds known to be potent activators of protein kinase C (Castagna et al., 1982; Nishizuka, 1984), have been found in the hippocampus (Murphy et al., 1983). Therefore, in the present study we have examined whether phorbol esters mimic the effect of ACh on the calcium-activated potassium conductance in CA1 pyramidal neurons. In addition, $\mathrm{ACh}$ is known to elicit a variety of other actions in the hippocampus, including a depolarization associated with a conductance decrease (Benardo and Prince, 1982; Cole and Nicoll, 1984a; Dodd et al., 1981), a blockade of a voltage-dependent potassium current, $I_{\mathrm{M}}$ (Halliwell and Adams, 1982), and presynaptic inhibition of excitatory transmission (Hounsgaard, 1978; Rovira et al., 1983; Valentino and Dingledine, 1981; Yamamoto and Kawai, 1967). We have examined whether these actions of $\mathrm{ACh}$ were also mimicked by protein kinase $\mathrm{C}$ activation. After submission of this paper, the report of Baraban et al. (1985b) appeared. Some of the present conclusions are in agreement with theirs.

\section{Materials and Methods}

The methods used in this paper are similar to those used in other studies from this laboratory (Nicoll and Alger, 1981). Briefly, rat hippocampal slices, $400 \mu \mathrm{m}$ thick, were cut and placed in a holding chamber for at least $1 \mathrm{hr}$. A single slice was then transferred to the recording chamber and held between two nylon nets, submerged heneath a continuously superfusing medium that had been pregassed with $95 \% \mathrm{O}_{2}, 5 \% \mathrm{CO}_{2}$ The composition of this medium was (mM): $\mathrm{NaCl}, 119 ; \mathrm{KCl}, 2.5 ; \mathrm{MgSO}_{4}$, $1.3 ; \mathrm{CaCl}_{2}, 2.5 ; \mathrm{NaH}_{2} \mathrm{PO}_{4}, 1.0 ; \mathrm{NaHCO}_{3}, 26.2 ;$ glucose, 11 . The temperature of the medium was maintained between 29 and $31^{\circ} \mathrm{C}$. Stock solutions of phorbol esters $(10 \mathrm{mM})$ were made in dimethyl sulfoxide (DMSO) and were diluted in oxygenated medium before administration. DMSO applied alone at concentrations considerably higher than those used in conjunction with phorbol esters failed to mimic the actions reported in this paper. In the experiments in which phorbol esters were tested on the M-current $\left(I_{\mathrm{M}}\right)$, it was important to demonstrate the sensitivity of the current to muscarinic receptor activation, since this is one of the properties used to define this current. This required applying 


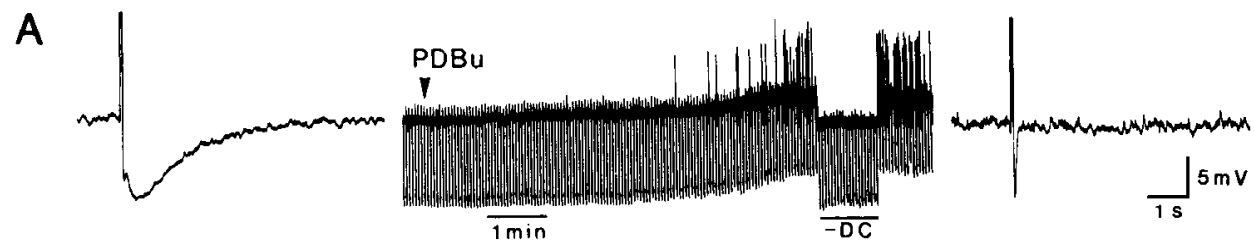

B

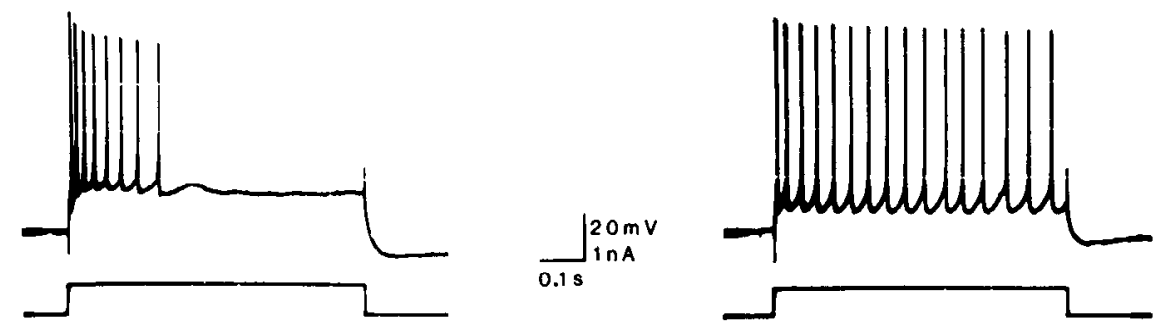

Figure 1. PDBu causes small depolarization of membrane potential and blocks both the slow AHP and accommodation. $A$, The AHP in response to a brief $(60 \mathrm{msec})$ depolarizing current pulse is shown at a fast chart speed. The chart speed was then reduced, and constant current hyperpolarizing pulses were applied at $0.3 \mathrm{~Hz}$. The superfusate was switched to one containing PDBu $(10 \mu \mathrm{M})$ at the arrowhead. During the interval labeled $-D C$, hyperpolarizing current was applied to repolarize the membrane potential to the control value. Little change in $R_{\text {in }}$ was seen. After 9 min in PDBu, the slow AHP had been abolished. $B$, Film records from the same cell of action potentials evoked by a 650 msec current pulse. Film records obtained within 1 min of the records of the AIIP in part $A$. Membrane potential, $-60 \mathrm{mV}$. The time calibration for the AIP in PDBu also applies to the control AHP. The voltage calibration applies to all chart records in $A$.

muscarinic agonists first, because phorbol esters appeared to antagonize the responses to muscarinic receptor activation on the M-current.

Conventional intracellular recording techniques were used for most of the experiments reported here. Intracellular electrodes were pulled from "omega dot" glass capillary tubing (O.D. $1.2 \mathrm{~mm}$, I.D. $0.6 \mathrm{~mm}$; Glass Co. of America) and were filled with $2 \mathrm{M}$ potassium methylsulfate $\left(\mathrm{KMeSO}_{4}\right.$; ICN Pharmaceuticals; electrode resistance 100-140 M $\Omega$ ).

To examine the effects of phorbol esters on potassium currents, singleelectrode voltage clamp techniques were used. Such recordings were made with an Axo-Clamp-2 single-electrode voltage clamp. Electrodes were pulled from thin-wall "omega dot" glass (O.D. $1.2 \mathrm{~mm}$, I.D. 0.9 $\mathrm{mm}$ ) and were filled with $3 \mathrm{M} \mathrm{KCl}$ (resistance 25-80 M 2 ). Electrodes were coated to within approximately $50-100 \mu \mathrm{m}$ of the tip with M-Coat D (Measurements Group Inc., Raleigh, NC) to reduce electrode capacitance. The voltage clamp head stage output was continuously monitored, and the switching frequency was adjusted to the maximum rate that still allowed the electrode voltage to settle completely between oscillations. A switching frequency of between 3 and $7 \mathrm{kHz}$ was usually obtained, depending on the characteristics of the electrode employed.

\section{Results}

In most of our studies, we have used the phorbol ester, phorbol12,13-dibutyrate $(\mathrm{PDBu})$, but we have obtained similar effects with 12-deoxyphorbol,13-isobutyrate, and phorbol-12,13-diacetate. Hippocampal pyramidal cells respond to short-duration (50-100 msec) depolarizing current pulses with a two-component afterhyperpolarization (AHP), the slower of which is mediated by a calcium-activated potassium conductance (Alger and Nicoll, 1980; Hotson and Prince, 1980; Schwartzkroin and Stafstrom, 1980). At $10 \mu \mathrm{M}$, PDBu completely abolished the slow component of the AHP within 5-10 min (Fig. $1 A ; n=41$ ). It has previously been found that a number of conditions that block the AHP also severely reduce spike frequency adaptation (Madison and Nicoll, 1982, 1984). This is also the case for the phorbol esters (Fig. $1 B$ ). This effect is essentially irreversible, since no recovery was seen after washing for more than an hour. Concentrations of phorbol esters below $10 \mu \mathrm{M}$ were also effective, but longer applications were required to produce an effect. For $1 \mu \mathrm{M}$, it took approximately $30 \mathrm{~min}$ to block the AHP and reduce accommodation $(n=4)$, whereas for $100 \mathrm{nM}$, AHPs were reduced only after applications of at least $1 \mathrm{hr}(n=8)$.

While the effect of PDBu on the AHP could occur in the absence of any change in membrane potential or input resistance, in the majority of cells $(68 \%)$, PDBu $(10 \mu \mathrm{M})$ caused a
Figure 2. Inactive phorbol esters do not block the AHP. At the top, a continuous record of the application of the inactive analog $4 \alpha$-phorbol-12,13didecanoate $(10 \mu \mathrm{M})$ begins at the $a r$ rowhead and continues until $\mathrm{PDBu}(10$ $\mu \mathrm{M})$ is applied at the arrowhead in the lower record. AHPs were elicited every $15 \mathrm{sec}$ during this experiment. Membrane potential, $-58 \mathrm{mV}$. Voltage calibration applies to all records. Slice was bathed in $0.3 \mu \mathrm{M}$ TTX and 5.0 $\mathrm{mM}$ tetraethylammonium (TEA) throughout this experiment.

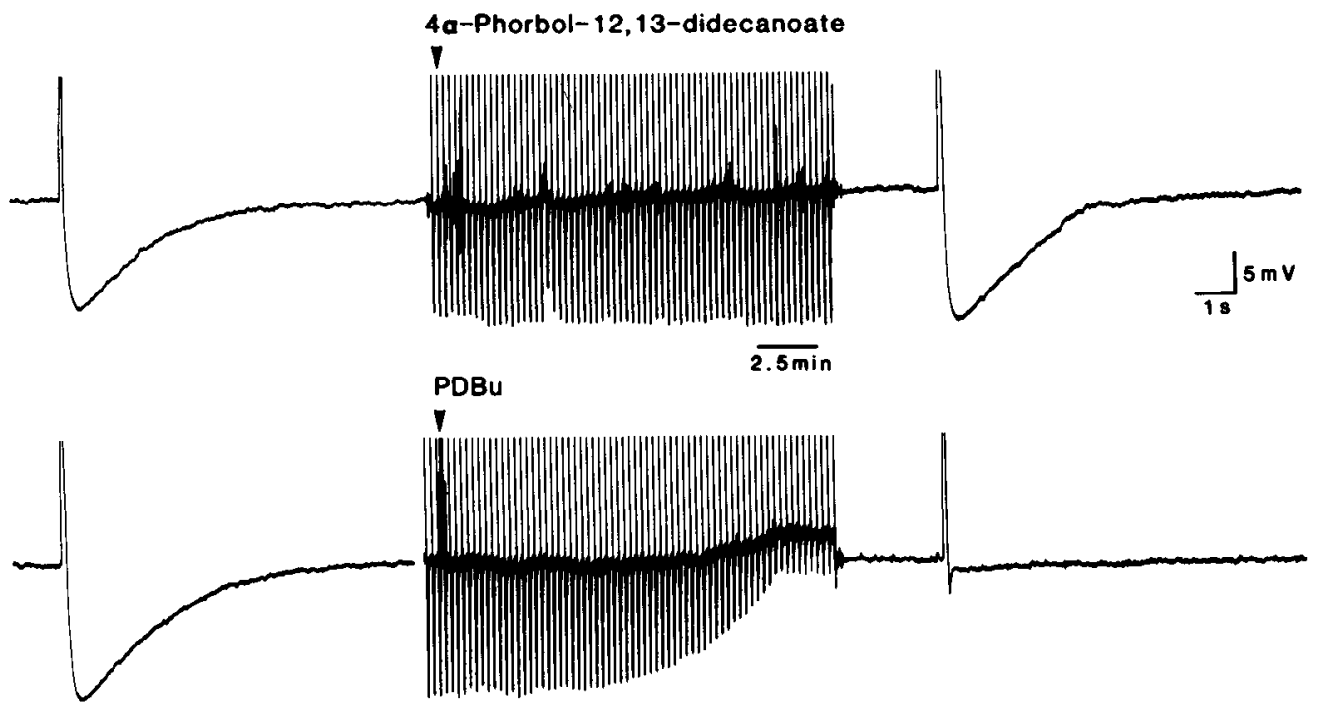



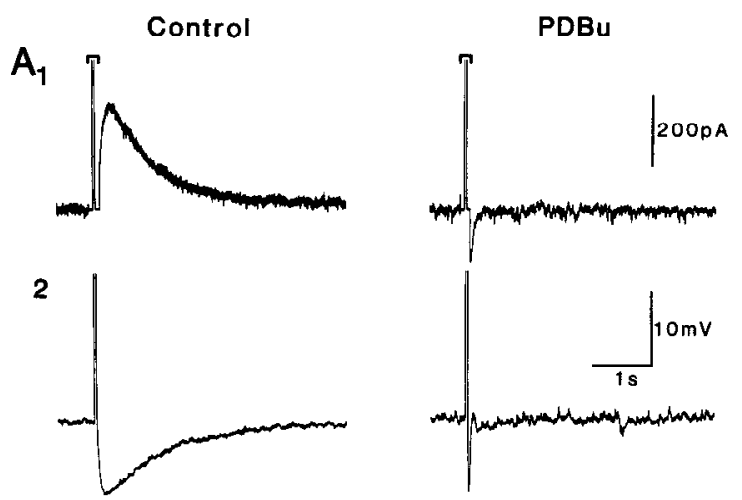

B
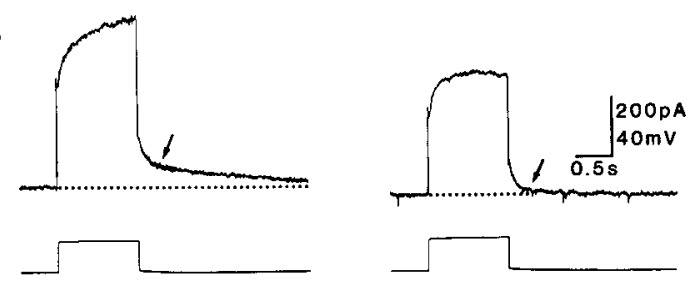

Figure 3. Phorbol esters reduce calcium-activated potassium currents in $\mathrm{C} \Lambda 1$ pyramidal cells. $A$, Chart records showing the results of experiments using a hybrid current/voltage clamp protocol. 1 , The cell was held in voltage clamp at a holding potential equal to the resting potential $(-61 \mathrm{mV})$. At the time indicated by the bracket, the voltage clamp was switched off briefly $(100 \mathrm{msec})$. Concurrently, the cell was stimulated with a depolarizing current pulse that caused the cell to fire action potentials, after which the voltage clamp was switched back on to measure the resulting membrane current. The outward current resulting from this stimulation is shown in control and $10 \mathrm{~min}$ after bath application of $10 \mu \mathrm{M}$ PDBu. 2, The AHP from the same cell elicited by an identical stimulus recorded entirely in current clamp. $B$, Voltage clamp records from another cell showing the outward relaxation that occurs when the cell is stepped from -60 to $-40 \mathrm{mV}$ and the tail current (arrow) that results when the membrane potential is stepped back to $-60 \mathrm{mV}$. This outward current and tail are shown in control and after $10 \mathrm{~min}$ in 10 $\mu \mathrm{M}$ PDBu. The voltage trace is positioned below the current trace.

small depolarization $(4.0 \pm 2 \mathrm{mV}, n=17)$ of the membrane potential. Unlike muscarinic depolarization, in most cells there was no apparent change in input resistance (Fig. $1 A$ ) or a small decrease.

It has been found in a number of systems that some analogs of phorbol are not effective in activating protein kinase C (Cas- tagna et al., 1982). To examine whether the effects observed following phorbol ester administration were mediated by this protein kinase, inactive analogs of phorbol were used. As shown in Figure 2, the inactive phorbol ester, $4 \alpha$-phorbol-12,13-didecanoate $(10 \mu \mathrm{M})$ did not reduce the AHP and caused no change in the membrane potential $(n=6)$, while PDBu applied to the same cell was fully effective in reducing the AHP. $4 \beta$-Phorbol was also without effect $(n=4)$.

The actions of phorbol esters under current clamp did not in all respects appear to mimic muscarinic responses, since they caused no consistent increase in input resistance. Hence, we chose to examine their actions under voltage clamp, where individual currents could be clearly separated. We first examined the current that underlies the AHP $\left(I_{\mathrm{AHP}}\right)$ with a single electrode voltage clamp. Two procedures were used. First, we used a hybrid current/voltage clamp protocol (Pennefather et al., 1985) in which the cell was taken out of voltage clamp immediately before evoking a series of action potentials with a depolarizing current pulse and switched back into voltage clamp immediately after the pulse. Figure $3 A, 1$ shows the outward current evoked by such a train of action potentials and the abolition of this current by phorbol esters $(n=3)$. The abolition of the AHP in this same cell, recorded in current clamp mode, is also shown (Fig. 3A, 2). In the second protocol, the cell was held continuously in voltage clamp at approximately $-60 \mathrm{mV}$ and $1 \mathrm{sec}$ duration depolarizing commands were applied. As seen in Figure $3 B$, depolarizing the cell to $-40 \mathrm{mV}$ evoked a slowly developing large outward current. Repolarizing the cell to -60 $\mathrm{mV}$ resulted in a prolonged outward tail current. PDBu grcatly reduced the time-dependent outward current and the tail $(n=5)$.

We have also used the voltage clamp to study possible effects of phorbol esters on the M-current $\left(I_{\mathrm{M}}\right) . I_{\mathrm{M}}$ is a time- and voltage-dependent potassium current that is blocked by muscarinic receptor activation (Halliwell and $\Lambda$ dams, 1982). This current is seen most clearly when cells are held at depolarizied potentials $(-30$ to $-40 \mathrm{mV})$ and are then stepped 10 to $20 \mathrm{mV}$, hyperpolarized for about $1 \mathrm{sec}$. Hyperpolarization, which closes M-channels, results in a time-dependent inward relaxation of membrane current. In Figure 4, we have compared the effects of muscarinic receptor activation, using carbachol, to PDBu on the M-current. While carbachol $(10-40 \mu \mathrm{M})$ produced large inward shifts in holding current and blocked the M-current, $\mathrm{PDBu}$ produced only small inward shifts in holding current and had no effect on the M-current. The M-current in all nine cells tested was unaffected by PDBu.

One possible mechanism that could account for the blockade of the calcium-activated outward currents is that calcium influx

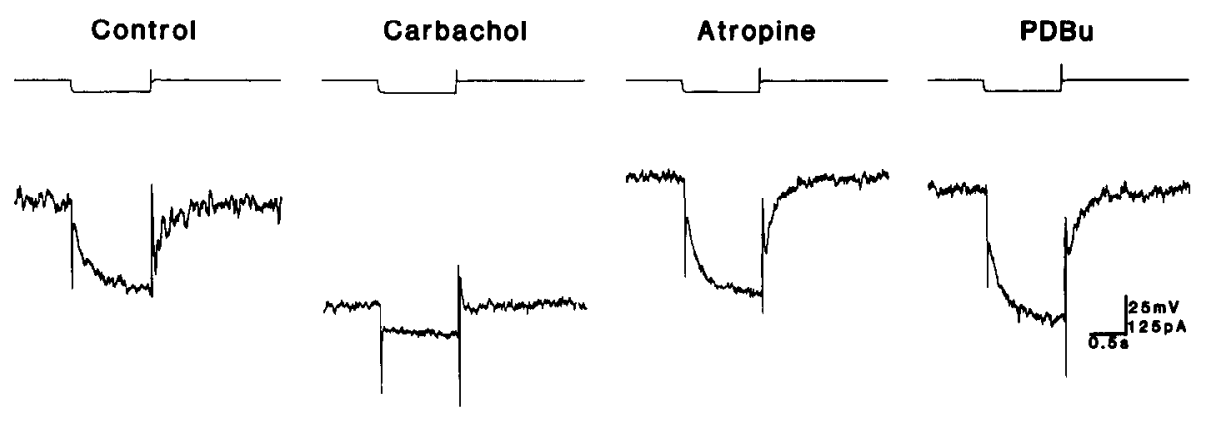

Figure 4. Phorbol esters do not reduce the M-current $\left(I_{M}\right)$ in CAl pyramidal cclls. The illustrated ccll was hcld in voltage clamp at a potential of $-40 \mathrm{mV}$ and stepped to $-50 \mathrm{mV}$ for $1 \mathrm{sec}$. This step resulted in a time-dependent inward relaxation of membrane current. In this experiment, the electrode contained $0.5 \mathrm{M}$ cAMP (with $3 \mathrm{M} \mathrm{KCl}$ ) to eliminate possible contamination by calcium-activated potassium current. Carbachol (10 $\mu \mathrm{M}$ ) was applied and caused an inward shift in holding current and a blockade of the inward relaxation to hyperpolarizing steps (record shown 12 min after application), confirming that this relaxation was due to closure of $\mathrm{M}$-current channels. Carbachol was washed from the chamber and atropine $(10 \mu \mathrm{M})$ was added to the bath to facilitate the recovery of the M-current relaxation (record shown after $25 \mathrm{~min}$ ). In some cells, atropine was not used, but this did not affect the result of the experiment. Following this recovery, $10 \mu \mathrm{M}$ PDBu was added to the medium and did not reduce the M-current even after $30 \mathrm{~min}$. The voltage trace is positioned above the current trace. 
Figure 5. Phorbol esters do not reduce calcium action potentials. The slice was bathed in a solution containing $0.3 \mu \mathrm{M}$ TTX and $5 \mathrm{~mm}$ TEA. $A$, Calcium spike (upper trace) evoked by depolarizing current pulse. The current monitor for the pulse is shown in the lower trace. The response to a subthreshold pulse is also superimposed on the record. The right-hand record is a superimposition of the control calcium spike and that evoked in the presence of PDBu $(5 \mu \mathrm{M})$ applied for $10 \mathrm{~min}$. $B$, Chart records of the after-hyperpolarization produced by the calcium spikes illustrated in $A$. Membrane potential, $-58 \mathrm{mV}$.
Control

A

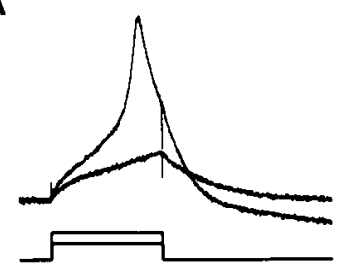

B

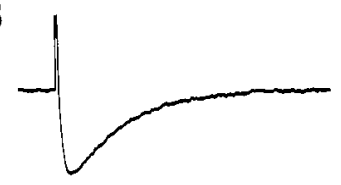

PDBu
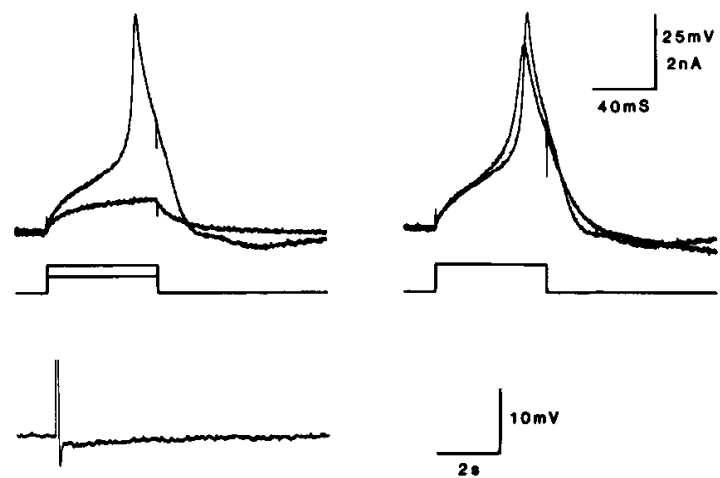

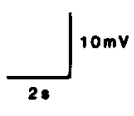

is reduced by phorbol esters. To examine this possibility we have recorded calcium spikes in the presence of tetrodotoxin (TTX; $0.3 \mu \mathrm{M}$ ) and tetraethylammonium (TEA; $5 \mathrm{~mm}$ ). At a time when PDBu had completely blocked the slow AHP, the calcium spike was still present (Fig. $5 A ; n=6$ ) with little change in its duration. In fact, there was often an increase in the peak amplitude of the spike. This result suggests that blockade of

A
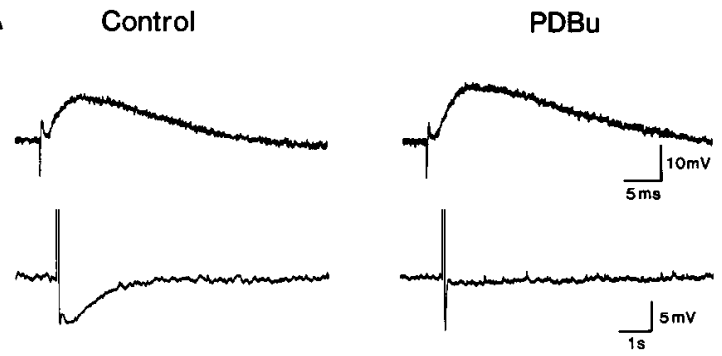

B
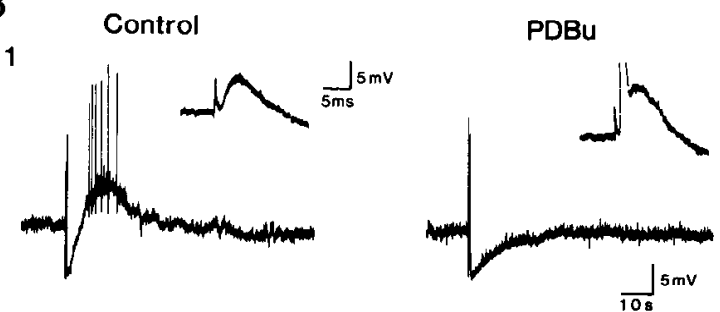

2

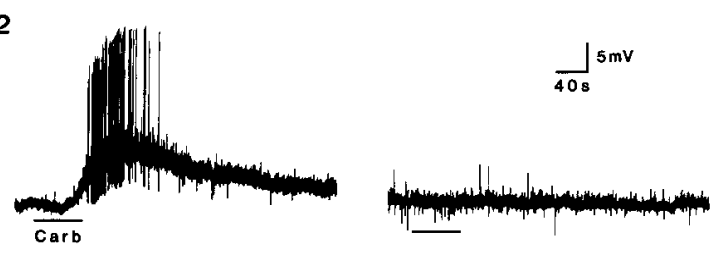

Figure 6. Actions of phorbol esters on fast and slow EPSPs. $A$, Fast EPSP, elicited by orthodromic stimulation, along with the AHPs from the same cell are shown before and $8 \mathrm{~min}$ after start of bath application of $10 \mu \mathrm{M}$ PDBu. The fast EPSP is larger when the slow AHP is completely blocked. Membrane potential, $-62 \mathrm{mV}$. Cell was hyperpolarized with direct current to $-75 \mathrm{mV}$ when EPSPs were elicited. $B, 1$, Slow cholinergic EPSP elicited by $30 \mathrm{~Hz}, 0.5 \mathrm{sec}$ stimulation in stratum oriens is completely blocked by $10 \mu \mathrm{M}$ PDBu. Inset shows the fast EPSP recorded from the same cell. Action potentials are truncated in both the chart record and inset. Membrane potential, $-59 \mathrm{mV} . B, 2$, The depolarization elicited by bath application of $5 \mu \mathrm{M}$ carbachol is completely blocked by $10 \mu \mathrm{M}$ PDBu. Action potential amplitude is again truncated by the chart recorder. Membrane potential, $-64 \mathrm{mV}$. calcium entry could not account for the blockade of the AHP.

Muscarinic agonists have been shown to have presynaptic inhibitory effects in the hippocampus (Hounsgaard, 1978; Rovira et al., 1983; Valentino and Dingledine, 1981; Yamamoto and Kawai, 1967). To test whether phorbol esters might share these presynaptic inhibitory actions, we have studied the effects of phorbol esters on two monosynaptic excitatory potentials, namely, the fast EPSP elicited by stimulating in stratum radiatum and the slow cholinergic EPSP elicited by high-frequency stimulation of cholinergic afferents in stratum oriens (Cole and Nicoll, 1984). At a time when PDBu had blocked the AHP, the fast EPSP elicited by orthodromic stimulation was not reduced and in most cases was considerably increased in amplitude (Fig. $6 A ; n=10$ ). On the other hand, PDBu entirely blocked the slow muscarinic EPSP (Fig. $6 B ; n=8$ ). Since this effect could possibly occur pre- or postsynaptically, we examined the effect of $\mathrm{PDBu}$ on the postsynaptic muscarinic excitations produced by bath-applied carbachol. In these experiments, PDBu effectively antagonized the depolarizing action of carbachol $(n=4)$.

If protein kinase $C$ activation mediates the blockade of the AHP caused by muscarinic agonists, one might expect other compounds, which are known to increase inositol phospholipid breakdown in cortical tissue, to have a similar action. Therefore, we bath-applied a number of these compounds. Phenylephrine acting on $\alpha_{1}$ receptors (10 $\left.\mu \mathrm{M}, n=9\right)$; substance $\mathrm{P}(10 \mu \mathrm{M}, n=$ 5); vasopressin (10 $\mu \mathrm{M}, n=5)$; and cholecystokinin (10 $\mu \mathrm{M}$, $n=3$ ) were all ineffective in reducing the AHP.

\section{Discussion}

Previous studies on hippocampal pyramidal cells have demonstrated that muscarinic receptor activation results in a membrane depolarization associated with a conductance decrease (Bcnardo and Prince, 1982; Cole and Nicoll, 1984a; Dodd et al., 1981) and blockade of both the M-current (Halliwell and Adams, 1982) and calcium-activated potassium conductance (Benardo and Prince, 1982; Cole and Nicoll, 1984a). Since work in a number of systems, including the hippocampus, has shown that muscarinic agonists induce inositol phospholipid breakdown and therefore presumably activate protein kinase $C$, we have examined whether directly activating this kinase using phorbol ester mimics the muscarinic actions of acetylcholine in the hippocampus. The major finding of this study is that phorbol esters exert a remarkably powerful and selective antagonism of the calcium-activated AHP and corresponding outward current. This was demonstrated in three ways. First, the slow AHP that follows a train of action potentials was abolished. Second, the outward current recorded under a hybrid current/voltage clamp protocol (Lancaster and Adams, 1984) was eliminated. Third, under voltage clamp, the time-dependent outward current that 
develops during a depolarizing command and the subsequent prolonged tail were severely reduced. This prolonged tail current has been shown to correspond to the current underlying the AHP (Adams and Lancaster, 1985). The block of the slow AHP could occur in the absence of any change in the cell's resting membrane properties (although a small depolarization often occurred). In addition, as would be expected from the results of previous studies from this laboratory (Madison and Nicoll, 1982,1984 ), blockade of the calcium-activated potassium current by phorbol esters resulted in a marked reduction in the accommodation of action potential discharge generated in response to long depolarizing stimuli.

Phorbol esters in a wide variety of tissues have been shown to activate protein kinase C directly. Since the block of the AHP only occurred with application of phorbol esters known to activate protein kinase $\mathrm{C}$ and not when inactive phorbol esters were applied, the block of the AHP is likely to be mediated by protein kinase $\mathrm{C}$. Concentrations of phorbol esters as low as $100 \mathrm{~nm}$ were effective in blocking the slow AHP and in reducing accommodation. However, with low concentrations of phorbol esters it often took up to an hour for the effects to develop fully. Furthermore, no recovery of the AHP was seen after washing the tissue with control solution for more than an hour. As suggested by others (Castagna et al., 1982), a likely explanation for the slow onset of action and lack of recovery is that phorbol esters are highly lipid soluble and once intercalated into the membrane may remain active for hours.

Norepinephrine, acting via $\beta$ receptor stimulation and subsequent increases in intracellular cAMP, blocks the slow AHP without reducing calcium action potentials (Madison and $\mathrm{Ni}$ coll, 1982). Similarly, phorbol esters appear to block the calcium-activated potassium current underlying the slow AHP without altering calcium influx. The actions of CAMP are thought to be mediated by activation of a cAMP-dependent protein kinase (protein kinase A) (Greengard, 1982). In a number of in vitro systems, phosphorylation of the same protein (possibly at different sites) by both protein kinase $\mathrm{C}$ and protein kinase $\mathrm{A}$ has been demonstrated (Takai et al., 1984). This raises the intriguing possibility that both protein kinase $C$ and protein kinase A act on a common membrane protein or group of proteins. The calcium-activated potassium channel would seem to be an especially ideal site for modification, since it appears to have potent effects on the cell's response to depolarizing stimuli. There are, however, several differences between the present results and those produced by $\beta$ receptor stimulation and cAMP. First, although norepinephrine and cAMP rarely block the slow AHP completely, application of phorbol esters almost always resulted in a complete abolition of the slow AHP. Second, $\beta$ receptor stimulation often results in a small depolarization associated with a conductance decrease (Madison and Nicoll, unpublished observations), whereas the small depolarization seen with phorbol esters was usually associated with a small increase or no change in conductance.

Since phorbol esters block the slow AHP, we tested a number of compounds, which have been reported to induce inositol phospholipid breakdown in the brain, to determine if they might also block the slow AHP. Phenylephrine, in cerebral cortex (Berridge et al., 1982) and hippocampus (Janowsky et al., 1984); substance $P$, in many regions, including hippocampus (Mantyh et al., 1984); vasopressin in hippocampus (Downes, 1982); and cholecystokinin in cerebral cortex (Downes, 1982) all increase inositol phospholipid breakdown but failed in our experiments to reduce the slow AHP. Similar negative results have been obtained by Haas and Konnerth (1983) for histamine acting on $\mathrm{H}_{1}$ receptors, which is known to increase inositol phospholipid breakdown (Berridge et al., 1982). Therefore, based on the above findings, the possibilities should be considered that the increase in inositol phospholipid breakdown induced by these com- pounds either does not occur in hippocampal CA1 pyramidal cells or that phorbol esters may have actions unrelated to those induced by inositol phospholipid breakdown.

Of all of the compounds we have tested that are known to increase inositol phospholipid breakdown, only muscarinic agonists block the AHP. However, some differences do exist between the actions of phorbol esters and muscarinic agonists. First, muscarinic receptor activation blocks $I_{\mathrm{M}}$, whereas phorbol esters have no effect on this current. Second, ACh exerts a potent muscarinic presynaptic inhibition of excitatory synapses in the hippocampus (Hounsgaard, 1978; Rovira et al., 1983; Valentino and Dingledine, 1981; Yamamoto and Kawai, 1967). Although phorbol esters had no depressant action on, and indeed increased the size of, the fast EPSP, they did abolish the slow cholinergic EPSP. This effect was consistent with a postsynaptic action of phorbol esters, since the depolarization elicited by direct application of carbachol was also blocked. This antimuscarinic action of phorbol esters is similar to that found in some smooth muscle preparations (Baraban et al., 1985a). The mechanism underlying this antagonism is unclear, but it has been found that phorbol esters inhibit carbachol-induced inositol phospholipid breakdown in the hippocampus (Labarca et al., 1984), providing rather indirect evidence that muscarinic actions may be linked to the breakdown of inositol phospholipids.

The question remains as to whether some muscarinic actions are mediated through protein kinase $\mathrm{C}$. Like carbachol, phorbol esters block the calcium-activated potassium current underlying the slow AHP, but they do not have the same consistent effects on membrane potential and input resistance nor do they block the M-current. Moreover, unlike ACh, they do not appear to exert a presynaptic inhibition of excitatory afferents. Thus, if inositol phospholipid breakdown is involved in muscarinic responses, the activation of protein kinase $\mathrm{C}$ can only account for part of the response. Until selective blockers of protein kinase $\mathrm{C}$ and phospholipase $\mathrm{C}$, the enzyme responsible for the breakdown of inositol phospholipid, are available, the involvement of inositol phospholipid breakdown in the electrophysiological actions of muscarinic receptor activation will remain inferential.

\section{References}

Adams, P. R., and B. Lancaster (1985) Components of Ca-activated $\mathrm{K}$ current in rat hippocampal neurones in vitro. J. Physiol. (Lond.) 362: 23P.

Aldenhoff, J. B., D. L. Gruol, J. Rivier, W. Vale, and G. R. Siggins (1983) Corticotropin releasing factor decreases postburst hyperpolarizations and excites hippocampal neurons. Science 221: 875-877.

Alger, B. E., and R. A. Nicoll (1980) Epileptiform burst after-hyperpolarization: Calcium-dependent potassium potential in hippocampal CAl pyramidal cells. Science 210: 1122-1124.

Baraban, J. M., R. J. Gould, S. J. Peroutka, and S. H. Snyder (1985a) Phorbol ester effects on neurotransmission: Interaction with neurotransmitters and calcium in smooth muscle. Proc. Natl. Acad. Sci. USA 82: 604-607.

Baraban, J. M., S. H. Snyder, and B. E. Alger (1985b) Protein kinase $\mathrm{C}$ regulates ionic conductance in hippocampal pyramidal neurons: Electrophysiological effects of phorbol esters. Proc. Natl. Acad. Sci. USA 82: 2538-2542.

Benardo, L. S., and D. A. Prince (1982) Ionic mechanisms of cholinergic excitation in mammalian hippocampal pyramidal cells. Brain Res. 249: 333-344.

Berridge, M. J., C. P. Downes, and M. R. Hanley (1982) Lithium amplifies agonist-dependent phosphatidylinositol responses in brain and salivary glands. Biochcm. J. 206: 587-595.

Castagna, M., Y. Takai, K. Kaibuchi, K. Sano, U. Kikkawa, and Y. Nishizuka (1982) Direct activation of calcium-activated, phospholipid-đependent protein kinase by tumor-promoting phorbol esters. J. Biol. Chem. 257: 7847-7851.

Cole, A. E., and R. A. Nicoll (1984a) Characterization of a slow cholinergic postsynaptic potential recorded in vitro from rat hippocampal pyramidal cells. J. Physiol. (Lond.) 352: 173-188. 
Cole, A. E., and R. A. Nicoll (1984b) The pharmacology of cholinergic excitatory responses in hippocampal pyramidal cells. Brain Res. 305 : 283-290.

Dodd, J., R. Dingledine, and J. S. Kelly (1981) The excitatory action of acetylcholine on hippocampal neurones of the guinea-pig and rat maintained in vitro. Brain Res. 207: 109-127.

Downes, C. P. (1982) Receptor-stimulated inositol phospholipid metabolism in the central nervous system. Cell Calcium 3: 413-428.

Greengard, P. (1978) Phosphorylated proteins as physiological effectors. Science 199: 146-152.

Haas, H. L., and A. Konnerth (1983) Histamine and noradrenaline decrease calcium-activated potassium conductance in hippocampal pyramidal cells. Nature 302: 432-434.

Halliwell, J. V., and P. R. Adams (1982) Voltage-clamp analysis of muscarinic excitation in hippocampal neurons. Brain Res. 250: 7192.

Hounsgaard, J. (1978) Presynaptic inhibitory action of acetylcholine in area CAl of the hippocampus. Exp. Neurol. 62: 787-797.

Hotson, J. R., and D. A. Prince (1980) A calcium-activated hyperpolarization follows repetitive firing in hippocampal neurons. J. Neurophysiol. 43: 409-419.

Janowsky, A., R. Labarca, and S. M. Paul (1984) Characterization of neurotransmitter receptor-mediated phosphatidylinosital hydrolysis in the rat hippocampus. Life Sci. 35: 1953-1961.

Labarca, R., A. Janowsky, J. Patel, and S. M. Paul (1984) Phorbol esters inhibit agonist-induced $\left[{ }^{3} \mathrm{H}\right]$ inositol-1-phosphate accumulation in rat hippocampal slices. Biochem. Biophys. Res. Commun. 123: 703-709.

Lancaster, B., and P. R. Adams (1984) Single electrode voltage clamp of the slow AHP current in rat hippocampal pyramidal cells. Neurosci. Abstr. 10: 872.

Madison, D. V., and R. A. Nicoll (1982) Noradrenaline blocks accommodation of pyramidal cell discharge in the hippocampus. Nature 299: 636-638.
Madison, D. V., and R. A. Nicoll (1984) Control of the repetitive discharge of rat CAl pyramidal neurones in vitro. J. Physiol. (Lond.) 354: 319-331.

Mantyh, P. W., R. D. Pinnock, C. P. Downes, M. Goedert, and S. P. Hunt (1984) Correlation between inositol phospholipid hydrolysis and Substance $P$ receptors in rat CNS. Nature 309: 795-79.7.

Murphy, K. M. M., R. J. Gould, M. L. Oster-Granite, J. D. Gearhart, and S. H. Snyder (1983) Phorbol ester receptors: Autoradiographic identification in developing rat. Science 222: 1036-1038.

Nicoll, R. A., and B. E. Alger (1981) A simple chamber for recording from submerged brain slices. J. Neurosci. Methods 4: 153-156.

Nishizuka, Y. (1984) Turnover of inositol phospholipids and signal transduction. Science 225: $1365-1370$.

Pennefather, P., B. Lancaster, P. R. Adams, and R. A. Nicoll (1985) Two distinct Ca-activated $\mathrm{K}$ currents in bullfrog sympathetic ganglion cells. Proc. Natl. Acad. Sci. USA 82: 3040-3044.

Rovira, C., Y. Ben-Ari, E. Cherubini, K. Krujevic, and N. Ropert (1983) Pharmacology of the dendritic action of acetylcholine and further observations on the somatic disinhibition in the rat hippocampus in situ. Neuroscience 8: 97-106.

Schwartzkroin, P. A., and C. E. Stafstrom (1980) Effects of EGTA on the calcium-activated afterhyperpolarization in hippocampal CA3 pyramidal cells. Science 210: 1125-1126.

Takai, Y., U. Kikkawa, K. Kaibuchi, and Y. Nishizuka (1984) Membrane phospholipid metabolism and signal transduction for protein phosphorylation. Adv. Cyclic Nucleotide Res. 18: 119-158.

Valentino, R. J., and R. Dingledine (1981) Presynaptic inhibitory effect of acetylcholine in the hippocampus. J. Neurosci. 1: 784-792.

Volle, R. L. (1983) Cyclic GMP in the nervous system. Fed. Proc. 42. 3098.

Yamamoto, C., and N. Kawai (1967) Presynaptic action of acetylcholine in thin sections from the guinea pig dentate gyrus in vitro. Exp. Neurol. 19: 176-187. 